\title{
A EFICÁCIA HORIZONTAL DOS DIREITOS HUMANOS E O TERCEIRO SETOR
}

\author{
José Fernando Vidal de Souza ${ }^{1}$ \\ Daiane Vieira Melo Costa ${ }^{2}$
}

RESUMO: O artigo aborda o fenômeno da constitucionalização no direito brasileiro e a aplicação dos direitos fundamentais nas relações privadas. Apresenta as diferenças dos direitos fundamentais e dos direitos humanos, com o reconhecimento da eficácia horizontal na aplicação destes na seara privada. A pesquisa é bibliográfica e os argumentos construídos com base no método dedutivo. Tem-se, ao final, que se as organizações privadas estão sujeitas aos deveres diante dos particulares, com maior razão devem estar as organizações do terceiro setor quanto à garantia e proteção dos direitos humanos,, por terem suas atividades muito mais próximas da atuação estatal. PALAVRAS-CHAVE: Direitos Humanos. Eficácia Horizontal. Terceiro Setor.

\section{THE HORIZONTAL EFFECTIVENESS OF HUMAN RIGHTS AND THE THIRD SECTOR}

\begin{abstract}
The article addresses the phenomenon of constitutionalisation in Brazilian law and the application of fundamental rights in private relations. It presents the differences of fundamental rights and human rights, with the recognition of the horizontal efficacy in the application of these in the private sector. The research is bibliographical and the arguments constructed based on the deductive method. Finally, it is concluded that if private organizations are subject to the duties of private individuals, the third-party organizations should be more concerned with the guarantee and protection of human rights, because their activities are much closer to state action.
\end{abstract}

KEYWORDS: Human Rights. Horizontal effectiveness. Third sector.

\section{INTRODUÇÃO}

O objetivo do presente artigo é discorrer sobre a atuação do terceiro setor na busca pela concretização dos direitos humanos no Estado Brasileiro. Para tanto, a pesquisa que será essencialmente bibliográfica, demonstrará que o paradigma da eficácia horizontal dos direitos fundamentais também se aplica aos direitos humanos após diferenciar os primeiros, reconhecidos internamente pelas constituições dos Estados, daqueles últimos reconhecidos a nível supraestatal, ou seja, em âmbito internacional. Em outras palavras, assim como para a

\footnotetext{
1 . Pós-doutor (CES da Universidade de Coimbra e UFSC). Mestre e Doutor em Direito (PUC-SP). Especialista em Ciências Ambientais pela USF. Bacharel em Direito e Filosofia (PUCCAMP). Professor da Uninove. Promotor de Justiça (MPSP).

2 . Mestranda em Direito pela Uninove. Especialista em Contabilidade Pública pela Unisul e Direito Processual Civil pelo Complexo Educacional Damásio. Bacharel em Direito pela Associação Educacional Toledo, Matemática pela Unesp e Pedagogia pela Uninove.
} 
concretização dos direitos fundamentais é possível que sejam sujeitos de deveres além do Estado, os particulares e as empresas, para a consecução dos direitos humanos também são responsáveis os particulares e o mercado, e consequentemente as organizações do terceiro setor por terem sua finalidade muito mais próxima da atuação estatal do que as empresas.

Para a concepção dos direitos humanos será utilizada a concepção histórica, segundo a qual tais direitos são frutos de uma luta histórica, na qual aqueles privados do Poder, viramse oprimidos e coibidos por seus próprios governantes, restando-lhes, tão somente, o direito de resistência, como último subterfúgio para rebater aludida violência.

É certo que nunca se falou tanto em direitos próprios ao ser humano do que logo após o período em que mais se massacrou tais direitos: a Segunda Grande Guerra Mundial. Diante das atrocidades cometidas contra a humanidade, especialmente nos governos tiranos nazistas e fascistas, em que paulatinamente os humanos foram perdendo sua humanidade e consequentemente violentados em sua integridade, submergiu a consciência coletiva ocidental da dignidade da pessoa humana.

Ao se limitar a consciência coletiva como ocidental não se faz por excluir tal consciência dos nativos do oriente, mas sim pelo desconhecimento da aplicação dos princípios aqui trabalhos naquela cultura.

Este novo paradigma da concepção dos direitos humanos no ocidente, tem como postulado o limite para atuação daqueles que detém o poder, qual seja, o respeito à dignidade da pessoa humana. Quanto a isto, cabe o referencial histórico de que o poder antes do século XIX esteve sempre concentrado nas forças estatais. Mesmo no período da Idade Média quando a igreja católica era sem qualquer sombra de dúvida a entidade mais poderosa, poder-se-ia dizer que o Estado era o detentor das regras, pois neste período a igreja e o Estado confundiam-se, como uma única força de duas nuances.

Após o período da globalização, com o fim das barreiras comerciais entre os Estados, e ainda, a grande revolução tecnológica que aproximou todos os povos do planeta, o Estado tal como era concebido passa a ter sua soberania relativizada e, consequentemente, outros poderes que sempre existiram, mas que jamais tiveram tanta influência, como é o caso do mercado financeiro, alargaram suas proporções de poder, e trouxeram novos questionamentos, ainda longe de serem solucionados, como o da possibilidade de se cobrar de organizações privadas ações positivas que antes eram demandadas apenas do Estado. 
Nesta linha de raciocínio em que o mercado adquire a feição de se igualar ao poderio estatal, a ordem das coisas passa a ser o interesse do próprio mercado e, portanto, se mantém a condição de dominador. Assim, o direito último de resistência, que antes era exercido apenas perante o Estado, passa a também a sê-lo frente ao grande capital.

Desta forma, o respeito aos direitos humanos como um todo passa a ser interesse do próprio mercado enquanto sujeito que pretende manter-se na situação. É neste que emerge a teoria da eficácia horizontal dos direitos fundamentais.

Utilizando-se do método dedutivo, com base em fontes indiretas, as considerações feitas neste trabalho serão no sentido de adaptar a argumentação da eficácia horizontal dos direitos fundamentais para a dos direitos humanos, considerando-se aqui como agente de responsabilização as organizações do terceiros setor, aqui concebidas como aquelas cuja finalidade é sempre de natureza não lucrativa, voltadas para a prestação de um serviço social nas áreas da saúde, educação, cultura e preservação do meio ambiente.

\section{A EFICÁCIA HORIZONTAL DOS DIREITOS HUMANOS NO BRASIL}

Não obstante o título desta seção limite os direitos humanos ao Estado brasileiro, estes se diferenciam dos ditos direitos fundamentais por terem seu reconhecimento em âmbito supraestatal, especialmente, pelos Tratados e Convenções assinados pelos Estados-nações, dos quais os principais em que o Brasil é signatário são: a Declaração Universal dos Direitos Humanos e a Convenção Americana dos Direitos Humanos (Pacto de San José da Costa Rica). Entretanto, na espécie a limitação refere-se às regras atinentes à eficácia horizontal destes direitos, tendo em mira o ordenamento jurídico brasileiro.

Atente-se, no entanto, que a grande maioria dos direitos expostos em tais cartas estão internalizados pela Constituição Federal de 1988 com a roupagem de direitos fundamentais, especialmente em seu art. $5^{\circ}$. Acresce-se a isto, o fato de a Emenda Constitucional $\mathrm{n}^{\circ} .45$ ter introduzido o $\S 3^{\circ}$ ao art. $5^{\circ}$ da $\mathrm{CF} / 88$ pelo qual os tratados e convenções internacionais sobre direitos humanos, aprovados pela Câmara e Senado, em dois turnos, por três quintos dos votos serem equivalente às emendas constitucionais, ou seja, tendo natureza constitucional também são direitos fundamentais.

Rev. de Teorias da Just., da Decisão e da Argumentação Jurídica | e-ISSN: 2525-9644 | Brasília | v. 3 | n. 1 | p. 1 - 19 | Jan/Jun. 
Logo, é natural que haja certa confusão nos conceitos de direitos fundamentais e humanos já que muitos deles se coincidem.

De fato, como explica Sarlet (2011, p. 31) várias são as expressões empregadas para designar direitos fundamentais, a saber: "direitos humanos, direitos do homem, liberdades públicas, direitos subjetivos públicos, direitos individuais e até direitos civis". Por isso, ele ensina a necessidade de se diferenciar tais direitos:

O fator diferencial é o local onde estão previstos esses direitos. Os direitos fundamentais estão reconhecidos e protegidos pelo direito constitucional de cada Estado, previstos no texto constitucional; os direitos humanos estão presentes em tratados internacionais, na esfera dos direitos internacionais e os direitos do homem são inerentes à condição de seres humanos (direitos naturais), ainda não positivados (SARLET, 2011, p. 34)

Assim, considerando que os direitos ora fundamentais, ora humanos consistem em um rol aberto, que vai sendo, via de regra, ampliado no decorrer do tempo, quanto ao aspecto relacionado a quem corresponde à asseguração destes direitos, tanto em um caso quanto no outro são válidos os mesmos argumentos utilizados, pois, como será discorrido ao longo deste capítulo, a eficácia horizontal se embasa nas teorias do Poder e do neoconstitucionalismo e não necessariamente na espécie de direito positivado, e muito menos na forma como este o foi.

Há uma imprecisão na definição de direitos humanos a qual recai à famigerada tautologia ou redundância, pois os direitos humanos são aqueles próprios do homem enquanto homem. Assim, furtando-se da tentativa de melhor conceituar os direitos aqui tratados, trazendo as lições de Bobbio (2004) e Comparato (2008) quando afirmam que não existem direitos atinentes à natureza humana, e sim direitos historicamente reconhecidos, dada a relatividade dos direitos diante do contexto histórico em que são analisados, chamar-se-ão de direitos humanos todos aqueles insertos dentro das chamadas gerações/dimensões de direitos, partindose dos direitos de liberdade, para a demanda por igualdade, e finalmente, aos direitos de solidariedade.

Sem aprofundar no tema, será aberto aqui um breve parêntese no sentido de que a divisão dos direitos em gerações/dimensões é meramente didática, e corresponde às modificações das atribuições estatais que ideologicamente se iniciam com o Estado Liberal para a passagem ao Estado Social. Num primeiro momento, exigia-se do Estado uma conduta 
negativa de modo a não intervir na economia, pois, supunha-se que os mercados eram autorreguláveis.

Contudo, a realidade demonstrou que a não interferência do Estado acentuou as desigualdades sociais que já existiam, e emergiram novas exigências à atuação estatal, que agora de maneira positiva deveria assegurar os direitos sociais, e por último, os ditos direitos de solidariedade, já com um enfoque no interesse da coletividade.

Neste sentido, Eros Grau (2015, p. 21-22) esclarece que: “à incapacidade de autorregulação dos mercados, conduziram à atribuição de novas funções do Estado. À idealização da liberdade, igualdade e fraternidade se contrapôs a realidade do poder econômico".

No entanto, no mundo fático brasileiro vê-se que não houve a consolidação sequer dos direitos de primeira geração, ou seja, os direitos de liberdade. Esta afirmação é tão verdadeira, na medida em que existe desigualdade social entre os seres humanos.

Com efeito, Amartya Sen endossa o entendimento de que não há que se falar em liberdade quando não se tem a mínima condição econômica de subsistência, uma vez, que nesta hipótese a capacidade de escolha está essencialmente limitada pelos recursos financeiros de que dispõe o sujeito. Por essa razão, o economista indiano ressalta que:

O desenvolvimento requer que se removam as principais fontes de privação de
liberdade: pobreza e tirania, carência de oportunidades econômicas e destituição
social sistemática, negligencia de serviços públicos e intolerância ou interferência
excessiva de Estados repressivos. A despeito de aumentos sem precedentes na
opulência global, o mundo global, o mundo atual nega liberdades elementares a um
grande número de pessoas - talvez até mesmo à maioria (SEN, 2013, p. 16-17).

Em razão de tais considerações a crítica apresentada por Vidal de Souza e Mezzaroba adquire força diante da realidade mundial atual ao afirmarem que:

Portanto, hoje mais do que em outras ocasiões, para se evitar confusões, utopias e quimeras, os direitos humanos precisam ser definidos com clareza. Por ser assim, são um problema amplamente filosófico, estreitamente político e nada jurídico, pois a sua consagração nos textos legais não surtem efeito de ordem prática e não conseguem alterar a realidade de um mundo capitalista, globalizado e neoliberal, dominado por leis de mercado, restrições monetárias e comerciais e marcado por intensas diferenças culturais (VIDAL DE SOUZA e MEZZAROBA 2012, p.207). 
De qualquer forma, para se analisar a eficácia horizontal dos direitos humanos, isto é, a possibilidade de se cobrar sua garantia não apenas verticalmente do Estado, mas horizontalmente, frente a particulares e outras instituições com ou sem fins lucrativos, que estão a princípio na mesma posição, parte-se aqui da concepção de que os direitos humanos são resultado da luta contra o poder. Por outras palavras trata-se da aplicação imediata dos princípios constitucionais que protegem a pessoa humana nas relações entre particulares, tanto na hipótese de uma das partes apresentar maior poder econômico ou social, como nas relações jurídicas entre iguais, tudo nos moldes do art. $5^{\circ} \S 1^{\circ}$ da $\mathrm{CF} / 88$.

Neste sentido, enfatiza-se a assertiva de Silveira e Rocasolano (2008, p. 95) ao explicarem os direitos humanos como fruto da luta contra o poder e a sua positivação como uma "forma de controlar e reduzir o poder estabelecido, mediante sujeição do poder aos ditames do direito".

Tudo isso, também, reforça a ideia de que positivação dos direitos humanos não foi ato de mera liberalidade dos governantes ao longo da história, mas sim, uma tentativa de evitar a violência advinda do emprego do direito de resistência. Por esta razão, precisa é a posição de Celso Lafer, (2015, p. 06), ao sustentar que os direitos humanos são "um freio democrático à discricionariedade e ao arbitrio dos governantes e dos poderosos".

Verifica-se, no entanto, que os direitos humanos não são violados apenas pelo Estado, mas também por outros agentes, como as empresas privadas, organizações não governamentais e até mesmo particulares. Como exemplos de atitudes de violações da dignidade humana nas relações privadas, poderia se ter um contrato de trabalho que obrigasse seus funcionários a revista íntima para evitar o furto de mercadorias, ou ainda, uma associação que impedisse a inclusão em seu quadro de associados um indivíduo homossexual.

Assim, para que se garanta a aplicação dos direitos fundamentais, além do Estado, caberia também a responsabilização dos demais atores sociais, sob pena de ter-se esvaziado o conceito de direitos próprios ao homem, por serem elevados à categoria de normas puramente programáticas e ideais a serem atingidos, muito mais utópico do que reais.

Diante dessas colocações, é certo que o discurso dos direitos humanos podem consolidar a democracia, mas como observa Leal:

No caso brasileiro, tanto os direitos humanos, como a política e a democracia não podem ter sentidos unívocos ou intrínsecos, porque encontram seu sentido na própria dinâmica conflitiva de seu espaço público. Assim, eles devem ser concebidos como 
um lugar de enfrentamento, que serve para mostrar o caráter absolutamente político do Direito e do Estado e a necessidade de problematizá-los através de práticas que politizem o jurídico (LEAL, 1997, p. 153).

A eficácia horizontal dos direitos humanos viria como resposta à efetividade destes direitos na esfera prática, posto que uma vez reconhecidos como invioláveis e derivados da própria condição humana, devem ser concretizados enquanto valor fundamental e implícito na filosófica ideia de pacto social que legitima a atuação dos detentores do Poder.

Estes ideais, são também explicáveis do ponto de vista da corrente neoconstitucionalista, construída a partir do século XX, pela qual as normas Constitucionais devem se sobrepor a todo o ordenamento jurídico de um país, inclusive às normas aplicáveis ao Direito Privado, com a interpretação segundo a Constituição Federal. Todavia, considerando a possibilidade de existirem direitos reconhecidos supranacionalmente e não inclusos na Carta Constitucional Brasileira, tampouco aprovados nos moldes da já referida emenda constitucional 45, optar-se-á pela justificativa da teoria do poder.

Ainda quanto à eficácia horizontal dos direitos fundamentais, mister se faz observar que segundo as lições de Gomes e Sarmento (2011), a origem deste instituto se deu na Alemanha, sendo objeto de análise de diversos países. Na Alemanha, segundo os autores, a doutrina dominante e os Tribunais reconheceram a eficácia horizontal dos direitos fundamentais nas relações privadas apenas de maneira mediata e não direta como se pretende no Brasil. Este posicionamento intermediário teria como fundamento a necessidade de garantir a segurança jurídica nas relações privadas, posto que o reconhecimento da vinculação direta das relações privadas ao teor dos direitos fundamentais daria uma margem muito grande de subjetividade na análise do julgador, além disso, haveria a extirpação da autonomia da vontade que rege as relações privadas.

A Constituição da República Portuguesa de 1986, dispondo sobre a força jurídica da Carta Constitucional, prevê expressamente em seu art. 8.1 que "Os preceitos constitucionais respeitantes aos direitos, liberdades e garantias são directamente aplicáveis e vinculam as entidades públicas e privadas", ou seja, previu expressamente a aplicação dos direitos fundamentais nas relações privadas.

A Constituição Brasileira de 1988, no entanto, é omissa quanto a esta possibilidade, o que não impede a sua aplicação, com fulcro na interpretação sistêmica dos dispositivos 
constitucionais e do paradigma do neoconstitucionalismo que ressalta a força jurídica dos dispositivos constitucionais em toda a legislação infraconstitucional do país, inclusive às normas aplicáveis ao direito privado.

De fato, como observa Sarlet (2011, p. 383), a CR/88 permaneceu silente quanto à vinculação dos direitos fundamentais e limitou-se a destacar a sua aplicação imediata, por isso o postulado constitucional (art. $5^{\circ} \S 1^{\circ}$ ) "pode ser compreendido como um mandado de otimização de sua eficácia, pelo menos no sentido de impor aos poderes públicos a aplicação imediata dos direitos fundamentais, outorgando-lhes, nos termos desta aplicabilidade, a maior eficácia possível".

Assim, tem-se que aqui um evidente conflito principiológico entre o princípio da autonomia da vontade que rege as relações entre os particulares, pautada no direito à liberdade, e o princípio da dignidade da pessoa humana, fundamento da Constituição pátria.

Além disso, não se pode esquecer que o modelo processual brasileiro admite a defesa dos direitos sociais tanto pela via individual, como pela via coletiva, o que representa um avanço, mas na realidade pátria tem causado uma série de problemas. Nesse sentido, Sarmento observa que:

(...) o Poder Judiciário brasileiro tem se mostrado, de um modo geral, muito mais generoso nas ações individuais do que nas coletivas, o que, na minha opinião, gera uma grave distorção em prejuízo da tutela dos direitos dos mais necessitados e da racionalidade do sistema. Por outro lado, na tutela coletiva, os magistrados não tem como escapar de uma reflexão que deveria ser realizada sempre que estivessem em jogo pretensões sobre recursos escassos: o potencial de universalização (SARMENTO, 2009, p. 174-175).

Diante de todas essas colocações, para solucionar a problemática apontada esta explanação se valerá das regras de colisão de princípios exposta pelo jurista alemão Alexy (2008), o qual diferencia as regras dos princípios, sendo tanto um quanto o outro, espécies do gênero normas jurídicas.

Dentre os critérios utilizados para se fazer a diferenciação entre regras e princípios tem-se o da generalidade, segundo o qual os princípios seriam normas com grau de generalidade mais elevado que as regras. Mas, além da diferença gradual, haveria também uma diferença qualitativa, isto é, os princípios são mandamentos de otimização, enquanto as regras são normas que são sempre satisfeitas ou não satisfeitas, de tal sorte que entre um conflito de regras se uma 
delas é válida e a outra não, salvo se houver uma regra de exceção que compatibilize a existência concomitante de duas regras aparentemente contraditórias.

Enquanto mandamento de otimização, a colisão entre princípios é resolvida por meio da atribuição de pesos aos princípios examinados, segundo as condições do caso concreto, havendo, portanto, uma graduação de ordem jurídica, uma vez que diante dos fatos um princípio poderá ser mais ou menos valorado. Desta maneira, nenhum princípio é declarado inválido diante de outro princípio por ter sido preterido diante de uma situação concreta, assim como também nenhum princípio pode ser absoluto, por mais alto grau de certeza se tenha de que ele deva prevalecer diante de outros, como é o caso da dignidade da pessoa humana.

Conclui-se, portanto, que o respeito aos direitos humanos, enquanto princípio da dignidade humana pode ser compatibilizado com o princípio da autonomia da vontade dos contratos, devendo ser feito o sopesamento diante do caso concreto. Os particulares gozando de sua autonomia da vontade poderiam livremente dispor de alguns direitos desde que com isso não violasse a dignidade humana, sendo este princípio um limitador daquele.

É evidente que esta solução deixa uma grande margem de subjetividade no julgamento para se decidir quando a dignidade humana é violada, pois este conceito é um tanto que aberto e valorado segundo os ideais de cada indivíduo, ou seja, o que para uma determinada parcela da sociedade pode ser absolutamente normal, para outra pode parecer uma afronta à sua dignidade.

Não obstante, é sabido que o desenvolvimento econômico é um fator que contribui para a efetivação dos direitos humanos, não podendo ser desconsiderados de qualquer análise. De fato, o índice de desenvolvimento humano (IDH) que mede o progresso de uma população levando em conta outros fatores e não necessariamente o desenvolvimento econômico, não deixou de incluir a renda entre um dos fatores de desenvolvimento, apenas acrescendo aspectos relacionados à saúde e educação passando para uma perspectiva voltada à qualidade de vida.

Se o desenvolvimento econômico é essencial para a concretização dos direitos humanos, é importante que o sistema jurídico como um todo possua regras estáveis para que estimule o crescimento, e não afugente o capital do país, o qual vê na insegurança jurídica um motivo desestimulador de investimento em um país. 
Assim, embora plausível a vinculação direta dos direitos humanos nas relações particulares, é importante que esta regra seja positivada no ordenamento jurídico brasileiro, mas essa discussão não pode ser enclausurada pelo discurso jurídico, pois como adverte Trindade:

\begin{abstract}
Continuamos convivendo com a velha contradição dos tempos da primeira Revolução Industrial: nunca a ciência, a técnica e os meios produtivos dispuseram de tantas e tão concretas possibilidades para a dar um fim a velhos males (fome, subnutrição, moléstias infecciosas, carência de habitação, distribuição desigual da educação, etc.), mas a triunfante lógica da produção para o mercado e para o lucro privado impede que se libere o uso social dessas possibilidades extraordinárias. Socializar prejuízos, privatizar lucros - a velha fórmula voltou a impor-se com fôlego renovado nas sucessivas crises econômicas que fecharam o século XX e abrira esse século (TRINDADE, 2002, p. 209).
\end{abstract}

De fato, depois de todo o exposto é importante destacar que o Supremo Tribunal Federal já se manifestou sobre a temática da recepção da eficácia horizontal dos direitos fundamentais nas relações privadas em várias oportunidades, tais como: RE $n^{\circ}$. 160.222-RJ, Rel. Min. Sepúlveda Pertence, DJ de 01/09/1995; RE 158215 RS, Rel. Min. Marco Aurélio, publicação DJ 07/06/1996; RE 161243-DF, Rel. Min. Carlos Velloso, publicação DJ de 19/12/1997; RE no. 201819/RJ, rel. Min. Ellen Gracie (vencida), redação do acórdão Min. Gilmar Mendes, publicação DJ de 27.10.2006.

Tudo isso corrobora a visão de Warat (2004, p. 72) ao destacar que, "lamentavelmente a história da Declaração dos Direitos Humanos é uma história de violações e transgressões à escala mundial". Assim enfatiza o autor que "esta história cheia de frustrações é mais grave em países como o Brasil, onde a exclusão social, a pobreza, a fome, a desnutrição tornam extremamente dramática e dolorosa a situação para a maior parte de sua população".

Portanto, os direitos humanos nas relações particulares devem, pois, obedecer à advertência feita por Warat (2004, p. 72-73) ao observar que a identidade das pessoas, bem como a construção da sua subjetividade, o aprendizado do sentido e a administração conflitos dão-se de "modo pacífico através de uma pedagogia baseada numa concepção educativa dos direitos humanos" e, por isso, arremata, "as pessoas aprendem a se cuidar aprendendo a lutar pelo direito a ter direitos, e a realizar suas vidas em termos de direitos humanos".

\title{
2. AS ORGANIZAÇÕES DO TERCEIRO SETOR E A CONCRETIZAÇÃO DOS DIREITOS HUMANOS
}


O fenômeno da globalização econômica, social e cultural aproximou os povos e ao mesmo tempo relativizou a soberania dos Estados, enquanto elemento absoluto da ordem jurídica válida, trouxe um novo paradigma para o conceito de Estado.

De fato, o Estado Constitucional, na concepção de Peter Häberle (2008, p. 142), “é uma tal condição devido as suas três liberdades culturais: arte, ciência e religião".

Já o Estado Constitucional Cooperativo, visa adequar o seu ordenamento jurídico interno às normas supranacionais, especialmente em relação àquelas relativas aos direitos humanos.

Assim, o Estado cuja definição se dava pela tríade: povo, território e soberania, na pósmodernidade, com a volatilidade dos mercados, inclusive em razão de serem em grande parte modelos virtuais, com uma nova identidade reconstruída e voltada para a nova ordem mundial. De outro lado, a noção de cidadania antes concebida dentro de um Estado, caracterizando-se por ser homogênea e negadora das diferenças passa a ter como escopo a igualdade de acesso e o respeito à diferença.

Portanto, o Estado Constitucional Cooperativo nada mais é que o Estado Constitucional voltado para a perspectiva do Direito Internacional, pressupondo a cooperação entre os Estados na busca pelo ideal comum entre os povos, constantes do reconhecimento de direitos inerentes à condição humana, e não apenas direitos de um cidadão enquanto pertencente a um Estado de Direito.

O Estado Constitucional cooperativo é aberto a outros Estados e Instituições Internacionais, voltado ao cidadão estrangeiro, partindo-se do postulado de defesa dos direitos fundamentais e humanos.

O jurista alemão Peter Häberle (2007), grande defensor do paradigma do Estado Constitucional Cooperativo, expõe que a cooperação internacional vai além da cooperação entre Estados, estando também voltado ao plano privado. Assim, as políticas estatais devem se voltar ao comércio de empresas multinacionais, desde que estas também estejam dispostas a se responsabilizar socialmente pelo desenvolvimento de suas atividades, havendo, portanto, uma colaboração entre os setores públicos e privados na concretização dos direitos humanos. 
Além das empresas, as Organizações Internacionais Não Estatais também são parte neste processo cooperativo nas relações internacionais, tendo o seu reconhecimento expresso no art. 71 da Carta das Nações Unidas. Estas Entidades que não pertencem nem ao primeiro setor que é o Estado, tampouco ao segundo setor composto pelas empresas, são situadas como organizações pertencentes ao terceiro setor, por terem suas atividades voltadas a uma finalidade de interesse público e não ao lucro como ocorre com as organizações do segundo setor.

No âmbito internacional pode-se exemplificar a atuação da Organização da Cruz Vermelha que não é vinculada a nenhum Estado-nação, tendo sua finalidade voltada à proteção da vida e da dignidade de vítimas de conflitos internacionais, ou ainda o Greenpeace cujas atividades destinam-se à proteção do meio ambiente.

Por isso, Peter Häberle (2007, p. 72) enfatiza que "a ciência do Estado constitucional livre e democrático tem a sua própria tarefa: Ela somente pode subsistir se perceber, de forma conceitual-dogmática responsabilidade regional e global para além do Estado".

No Brasil, podemos de certa forma associar a história do terceiro setor com a dos direitos fundamentais, que vão se estabelecendo na medida em que as funções do Estado vão sendo modificadas ao longo do tempo.

Primeiramente, tem-se a figura do Estado liberal, preservador dos direitos de liberdade de seus cidadãos, com uma atuação muito mais negativa. Após a Revolução Industrial e o consequente surgimento de uma nova classe social - o proletariado, a sociedade passou a demandar do Estado uma atuação positiva, no sentido de assegurar os direitos de igualdade, tendo em vista a grande desigualdade social que evidenciava que as pessoas não estavam em pé de igualdade, não tendo as mesmas oportunidades de acesso. Neste contexto, a proteção dos direito sociais passa a ser a função primordial do Estado garantidor, tem-se aqui a figura do Estado Social.

Contudo, diante do alargamento das funções estatais e a ineficiência que este demonstrou na seara prática no objetivo de igualar as condições de seus cidadãos, além da crise financeira que se instaurou no Brasil, o qual se não se adequasse às regras do Fundo Monetário Nacional não poderia mais dispor de recursos do Banco Mundial, surge uma nova perspectiva das funções estatais, com o principal objetivo de diminuir os gastos públicos, o qual passou a ser denominado de Estado Democrático de Direito. Nesta nova concepção, o Estado Brasileiro passa por um processo de privatização o qual pode ser denominado em apertada síntese como 
medidas utilizadas com o intuito de diminui as atribuições estatais. De acordo com Pietro (2012), o conceito de privatização engloba medidas como: a desregulação (diminuição da intervenção do Estado no domínio econômico), a desmonopolizarão de atividades econômicas, formas privadas de gestão a exemplo da concessão de serviços públicos ou parcerias públicoprivadas, liberação de serviços públicos e as contracting out (colaboração com o setor privado por meio de convênios ou contratos).

Em outras palavras, privatizar significa reduzir a atuação do Estado em prol da iniciativa privada, diante do reconhecimento de que esta última é mais eficiente na prestação de serviços ao agora denominado cidadão-cliente.

A denominação Estado Democrático de Direito se baseia na participação popular nas decisões políticas, na modificação do princípio da legalidade antes de cunho meramente formalista, passando a conter a ideia de justiça material (Estado de Direito).

Tem-se aqui a figura do Estado subsidiário que intervém na economia apenas quando a iniciativa privada não tiver condições de fazê-lo. É neste contexto que as entidades sem finalidades lucrativas voltadas à prestação de serviços tipicamente públicos ganham relevância.

De fato, a Constituição Federal de 1988, no capítulo da Ordem Social, artigos 197 e 205, possibilita expressamente que os serviços de saúde e educação podem ser prestados por Entidades do Terceiro Setor.

Em outros casos, a Constituição Federal Brasileira deixa implícita a atuação das Organizações do Terceiro Setor, como se verifica da leitura do art. 204, que trata da assistência social e traça as diretrizes para as ações governamentais permitindo a descentralizaçãoadministrativa e a participação da população.

A ideia de subsidiariedade vem expressa no art. 170, enquanto que a de fomento está prevista nos artigos 215 (cultura), 217 (desporto) e 218 (ciência e tecnologia).

As Organizações do Terceiro Setor podem ser criadas com respaldo no direito de associação consagrado pelo art. $5^{\circ}$, inciso XX, podendo assumir as formas de associações, fundações, organizações religiosas ou partidos políticos, previstas no art. 44 do Código Civil Brasileiro.

Desta forma, os primeiros marcos regulatórios das Entidades do Terceiro Setor no Brasil são apresentados pelas leis $n^{\circ} .9 .637 / 98$ e 9.790/99, que instituíram as Organizações 
Sociais (OSs) e as Organizações da Sociedade Civil de Interesse Público (OSCIPs). Ambas possuem a natureza de pessoas jurídicas de direito privado, com finalidade não lucrativa que podem receber recursos públicos para a realização de suas atividades, as quais, via de regra, voltam-se ao ensino, pesquisa científica, saúde, cultura e preservação do meio ambiente. Os instrumentos legais que regulamentam as relações entre o Poder público e estas Organizações são o Termo de Parceria (OSCIPs) e o Contrato de Gestão (OSs).

Mais recentemente, foi promulgada a lei $\mathrm{n}^{\circ} .13 .019$ de 31 de julho de 2014, com vigência a partir de fevereiro de 2016, apelidada de "novo marco regulatório das ONGS", instituindo o termo de colaboração e o termo de fomento para as transferências de recursos públicos para as organizações da sociedade civil. O principal objetivo desta lei foi trazer regras mais rígidas às transferências de recursos públicos, e garantir maior transparência na gestão destas Entidades, uma vez que o objetivo de sua própria existência é a consecução de uma finalidade pública e não a fuga das rígidas regras licitatórias a que se submete a Administração Pública, constantes da Lei 8.666/83.

As entidades do Terceiro Setor são também conhecidas como entidades sem fins lucrativos, pois embora possam eventualmente lucrar, o resultado positivo de suas atividades não é distribuído entre os seus sócios, eis que pertence à sociedade, o que implica dizer que propósito institucional destas organizações é o de provocar mudanças sociais.

Desta forma, a aferição de lucro não descaracteriza tais entidades, eis que como explicam Vidal de Souza e Melo Costa (2016, p. 29) “é perfeitamente compreensível e esperado que no desenvolver de suas atividades exista um resultado positivo entre suas receitas e despesas". Contudo, "este será reinvestido dentro da própria organização com a finalidade ora de ampliar ou aprimorar a prestação do serviço social a qual foi instituída, com vistas à satisfação do cidadão-cliente".

Quanto às fontes de recursos para o seu financiamento, é certo que as Organizações do Terceiro Setor, além das transferências de recursos federais, estaduais e municipais, podem receber contribuições, doações e subvenções ou, ainda, auferir receitas com a venda de produtos, serviços ou remuneração de seu capital.

Por isso, a razão de ser das Organizações do Terceiro Setor é a de perseguir o interesse público, prestando serviços de natureza pública à população, com o fỉm de promover o bem- 
estar social e, em última análise, concretizar os direitos sociais, fundamentais e humanos em complemento à atuação estatal.

Enfim, quando se defende a eficácia horizontal dos direitos humanos na esfera privada, com muita razão deve-se atribuir este efeito às organizações do terceiro setor, por terem estas uma finalidade muito mais próxima àquelas estatais do que as empresas privadas.

\section{CONSIDERAÇÕES FINAIS}

$\mathrm{O}$ artigo tratou da possibilidade de se exigir a concretização dos direitos humanos perante as organizações do terceiro setor. No âmbito internacional, o reconhecimento na atuação destas organizações foi reconhecido expressamente pela Carta das Nações Unidas.

No Brasil, a criação destas organizações tem respaldo no direito de associação previsto na Constituição Federal Brasileira, e apesar de não haver uma regra expressa prevendo o reconhecimento destas entidades na busca pela concretude dos direitos humanos e fundamentais, a própria razão de ser destas organizações estão pautadas em uma modificação social, no sentido de contribuir para uma sociedade mais igualitária e humana.

Todavia, além deste enfoque, resta saber se estas organizações também podem ser sujeitas de deveres diante da violação dos direitos humanos, o que para tanto, utilizou-se o referencial teórico da eficácia horizontal dos direitos fundamentais, segundo o qual os particulares e empresas podem ser sujeitos de deveres na consecução dos direitos fundamentais.

Nos tópicos anteriores foi relatado que não há um dispositivo constitucional que obrigue outros agentes sociais, além do próprio Estado, ao cumprimento dos direitos fundamentais, no entanto, a vinculação imediata destes ao cumprimento daqueles direitos é compatível com o ordenamento jurídico brasileiro, uma vez que as normas constitucionais são dotadas de força normativa, e devem ser interpretadas de modo a possibilitar que seus mandamentos sejam efetivos, e não meros ideais programáticos e utópicos.

Trata-se, portanto, da visão neoconstitucionalista que implica na impregnação do mandamento constitucional em todas as normas de um Estado, inclusive àquelas de cunho privado.

Rev. de Teorias da Just., da Decisão e da Argumentação Jurídica | e-ISSN: 2525-9644 | Brasília | v. 3 | n. 1 | p. 1 - 19 | Jan/Jun. 
Além disto, apontou-se que os direitos humanos são resultado de uma luta histórica contra o Poder, o qual se antes era concentrado nas mãos dos governantes estatais, com o processo de globalização, e a consequente diluição do poder, podem ser cobrados também de organizações com ou sem fins lucrativos e até mesmo de particulares, ainda porque estes agentes também violam tais direitos.

Com efeito, percebe-se que a teoria da eficácia dos direitos fundamentais às relações privadas, fruto autonomia privada já se vê consagrada na doutrina e jurisprudência pátria, à vista do art. $5 \S 1^{\circ}$ da $\mathrm{CF} / 88$, que não restringe a aplicabilidade do dispositivo apenas ao Poder Público, mas o reconhece, também, diante das relações jurídicas estabelecidas entre particulares.

No tocante às organizações do terceiro setor, que possuem natureza híbrida de público e privada, a concretização dos direito humanos seria em última instância o fundamento de existência destas Instituições, as quais são criadas para a consecução de uma finalidade notadamente pública, e neste ponto, muito mais próximas da atuação estatal.

Porém, considerando que as organizações do terceiro setor são constituídas sob a forma de fundações e associações privadas e, portanto, são pessoas jurídicas de direito privado e não público, àqueles mais legalistas que não admitissem a inclusão destas organizações como sujeitas de deveres no âmbito dos direitos humanos, aplicar-se-ia a teoria da eficácia horizontal dos direitos humanos, nos mesmos moldes que se faz para as empresas privadas.

Embora as atividades das entidades do terceiro setor sejam voltadas a uma finalidade pública, inclusive tendo como uma das fontes de financiamento recursos governamentais, administrativamente estas organizações possuem colaboradores que não necessariamente são voluntariados, ou seja, possuem em seus quadros de funcionários empregados com vínculo trabalhistas regidos pela Consolidação das Leis do Trabalho (CLT). É justamente nas relações empregatícias que mais notadamente se percebe a violação dos direitos humanos, de modo que estas organizações são ao menos em tese possíveis violadoras destes direitos.

Entretanto, deve-se reconhecer que o bom andamento da economia de um país exige que as regras sejam bem definidas, de modo que o mercado não seja surpreendido por uma grande margem de subjetividade dos julgadores em suas decisões.

Diante desta constatação, conclui-se neste artigo que embora seja razoável a vinculação direta dos particulares no cumprimento dos direitos humanos, o ideal seria que os 
legisladores brasileiros, por meio de emenda constitucional incluíssem dispositivo nesta linha, nos mesmos moldes que o fez a Constituição de Portugal, encerrando, assim, com discussões cerebrinas desnecessárias e enfadonhas.

A pesquisa não se preocupou em demonstrar se as organizações do terceiro setor são mais eficientes que o Estado na prestação de serviços público, tampouco se às medidas de privatização e a visão do Estado Subsidiário tem respondido a contento as demandas sociais.

No presente artigo verificou-se que do ponto de vista legal é possível a atuação destas organizações, e que devem agir de maneira condizente com o cumprimento dos direitos humanos, tanto por terem suas atividades próximas às atividades estatais, quanto por estarem vinculadas da mesma maneira que qualquer organização privada diante da eficácia horizontal dos direitos humanos, pois as normas definidoras dos direitos e garantias fundamentais possuem aplicação imediata e não há um preceito constitucional que diga que a aplicabilidade dos direitos fundamentais deve ser diversa em se tratando da modalidade de cada uma relações, sejam elas, pública, privada ou mista.

Portanto, o tratamento dispensado às relações públicas, privadas e mistas deve ser idêntico, ou seja, para efeito da aplicação dos direitos fundamentais exige-se que o intérprete das normas vigentes vá além da simples leitura da existência do indivíduo, face o predomínio da eficácia horizontal dos direitos humanos, tudo para efeito de garantir uma sociedade justa, fraterna e igualitária.

\section{REFERÊNCIAS}

ALEXY, Robert. Teoria dos Direitos Fundamentais. (trad. Virgílio Afonso da Silva). São Paulo: Malheiros Editores, 2008.

BARROSO, Luís Roberto Curso de Direito Constitucional Contemporâneo - Os conceitos fundamentais e a construção do novo modelo. $2^{\mathrm{a}}$ ed. São Paulo: Saraiva, 2010.

BENACCHIO, Marcelo; NASPOLINI SANCHES, Samyra H. D. F. A efetivação dos direitos humanos sociais no espaço privado. In: BAEZ, Narciso; BRANCO, Gerson Luiz Carlos; PORCIUNCULA, Marcelo. (Orgs). A problemática dos direitos humanos fundamentais na América Latina e Europa: desafios materiais e eficaciais. Joaçaba: Editora da UNOESC, 2012. 
BOBBIO, Norberto. A era dos direitos. Rio de Janeiro: Elsevier, 2004.

BRASIL. Constituição da República Federativa do Brasil de 1988. Disponível em: http://www.planalto.gov.br/ccivil_03/Constituicao/Constituicao.htm. Acesso em 10. mai.. 2017.

LEI N 8.666, de 21 de junho. Regulamenta o art. 37, inciso XXI, da Constituição Federal, institui normas para licitações e contratos da Administração Pública e dá outras providências. Disponível em: < http://www.planalto.gov.br/ccivil_03/leis/L8666cons.htm>. Acesso em 20. mai. 2017.

LEI No 9.637, de 15 de maio de 1998. Dispõe sobre a qualificação de entidades como organizações sociais, a criação do Programa Nacional de Publicização, a extinção dos órgãos e entidades que menciona e a absorção de suas atividades por organizações sociais, e dá outras providências. < http://www.planalto.gov.br/ccivil_03/leis/L9637.htm>. Acesso em 20. mai. 2017.

LEI N 9.790, de 23 de março de 1999. Dispõe sobre a qualificação de pessoas jurídicas de direito privado, sem fins lucrativos, como Organizações da Sociedade Civil de Interesse Público, institui e disciplina o Termo de Parceria, e dá outras providências. Disponível em: < http://www.planalto.gov.br/ccivil_03/leis/L9790.htm>. Acesso em 20. mai. 2017.

LEI No 13.019, de 31 de julho de 2014. Estabelece o regime jurídico das parcerias entre a administração pública e as organizações da sociedade civil, em regime de mútua cooperação, para a consecução de finalidades de interesse público e recíproco, mediante a execução de atividades ou de projetos previamente estabelecidos em planos de trabalho inseridos em termos de colaboração, em termos de fomento ou em acordos de cooperação; define diretrizes para a política de fomento, de colaboração e de cooperação com organizações da sociedade civil; e altera as Leis nos 8.429, de 2 de junho de 1992, e 9.790, de 23 de março de 1999. Disponível em: <http://www.planalto.gov.br/ccivil_03/_ato20112014/2014/lei/113019.htm>. Acesso em 18. mai.2017.

COMPARATO, Fábio Konder. Afirmação histórica dos direitos humanos. $7^{\mathrm{a}}$ ed. São Paulo: Saraiva, 2008.

DI PIETRO, Maria Sylvia Zanella. Parcerias na Administração Pública. São Paulo: Atlas S.A., 2012.

DUARTE, Luciana Gaspar Melquíades; VIEIRA, Ana Carolina Oliveira. Papel do Estado na promoção da eficácia horizontal dos direitos fundamentais. Disponível em: < https://seminariosinternacionaisdireitoshumanoseempresas.files.wordpress.com/2015/10/pape 1-do-estado-ultima-versao.pdf> Acesso em 27/05/2016. 
GRAU. Eros Roberto. A Ordem Econômica na Constituição de 1988. $17^{\mathrm{a}}$ ed. São Paulo: Malheiros, 2015.

GOMES, Fábio Rodrigues; SARMENTO, Daniel. A eficácia horizontal dos direitos fundamentais nas relações entre particulares: o caso das relações de trabalho. Revista TST, vol. 77, nº 4. Brasília, 2011. Disponível em:

$<$ http://aplicacao.tst.jus.br/dspace/handle/1939/28342. Acesso em 27/05/2016.

HÄBERLE, Peter. O Estado Constitucional Cooperativo. Rio de Janeiro: Renovar, 2007. Os problemas da Verdade no Estado Constitucional - Wahrheitsprobleme im Verfassungsstaat. Trad. Urbano Carvelli. Porto Alegre: Sérgio Antonio Fabris Editor, 2008.

LEAL, Rogério Gesta. Direitos Humanos no Brasil - Desafios à Democracia. Porto Alegre: Livraria do Advogado; Santa Cruz do Sul: EDUNISC, 1997.

OLIVEIRA, Gustavo Justino de (Coordenador). Direito do Terceiro Setor. Belo Horizonte: Fórum, 2008.

ORGANIZAÇÕES DAS NAÇÔES UNIDAS (ONU). Carta das Nações Unidas. Disponível em: <http://www.planalto.gov.br/ccivil_03/decreto/1930-1949/d19841.htm>. Acesso em 28/05/2016.

LAFER, CELSO. Prefácio. In: PIOVESAN, FLÁVIA. Direitos Humanos e Justiça Internacional. $6^{a}$ ed. São Paulo: Saraiva, 2015.

PIOVESAN, Flávia. Direitos Humanos e o Direito Constitucional Internacional. $8^{\mathrm{a}}$ ed. São Paulo, Saraiva, 2007.

PORTUGAL. Constituição da República, 02 de Abril de 1976. Disponível em: <http://www.parlamento.pt/Legislacao/Paginas/ConstituicaoRepublicaPortuguesa.aspx > Acesso em 27/05/2016.

SARLET, Ingo Wolfgang. A eficácia dos direitos fundamentais: uma teoria geral dos direitos fundamentais na perspectiva constitucional. $10^{\mathrm{a}}$ ed. Porto Alegre: Livraria do Advogado Editora, 2011.

SARMENTO, Daniel. A proteção social dos direitos sociais: alguns parâmetros éticojurídicos. In: ARRUDA, Paulo (Org.) Direitos Humanos - Questões em Debate. Rio de Janeiro: Editora Lumen Juris, 2009, p. 141-182.

SEN, Amartya. Desenvolvimento como liberdade. $2^{\text {a }}$ reimpr. São Paulo: Companhia de Bolso, 2013.

Rev. de Teorias da Just., da Decisão e da Argumentação Jurídica | e-ISSN: 2525-9644 | Brasília | v. 3 | n. 1 | p. 1 - 19 | Jan/Jun. 
SOUZA, José Fernando Vidal de Souza; MEZZAROBA, Orides. Direitos Humanos no século XXI: uma utopia possível ou uma quimera irrealizável. In: BAEZ, Narciso; SILVA, Rogério Luiz Nery; SMORTO, Guido. (Orgs). Os desafios dos Direitos Humanos Fundamentais na América Latina e Europa. Joaçaba: Editora da UNOESC, 2012.

SOUZA, José Fernando Vidal de Souza; COSTA, Daiane Vieira Melo. O terceiro setor no contexto do desenvolvimento sustentável e da sustentabilidade. In: Direito ambiental e socioambientalismo I. Organização CONPEDI/UNICURITIBA; Coordenadores: Bartira Macedo Miranda Santos, José Fernando Vidal de Souza. Florianópolis: CONPEDI, 2016, p. $27-46$.

SILVEIRA, Vladmir Oliveira; ROCASOLANO, Maria Mendes. Direitos Humanos: conceitos, significados e funções. São Paulo: Saraiva, 2010.

TRINDADE. José Damião de Lima. História Social dos Direitos Humanos. $2^{a}$ ed. São Paulo: Peirópolis, 2002.

WARAT, Luís Alberto. Direitos Humanos: subjetividade e práticas pedagógicas. In: SOUSA Jr., José Geraldo de. et. al. (Orgs). Educando para os Direitos Humanos - Pautas

Pedagógicas para a Cidadania na Universidade. Porto Alegre: Síntese, 2004. 